\title{
PORTA-ENXERTOS PARA A CULTURA DO PÊSSEGUEIRO DO TERCEIRO MILÊEIO'
}

\section{FILIBERTOLORETI ${ }^{2}$}

RESUMO- O emprego de porta-enxertos sempre responde a modernas exigências pedidas por uma fruticultura tecnicamente evoluída, iniciou-se na Itália e, em geral, na Europa, a partir dos anos 60, mas assumiu importância com o desenvolvimento da fruticultura industrial. Para algumas espécies, dentre as quais particularmente a macieira e a pereira, este processo iniciou-se antes e evidenciouse com maior rapidez, tanto que, atualmente, vêm-se se usando exclusivamente porta-enxertos clonais. Para outras espécies, como o pessegueiro, o pedido de novos porta-enxertos é mais recente em conseqüência da difusão desta espécie ainda em zonas não de todo evocadas de um ponto de vista pedoclimático, o qual, a exemplo daquelas caracterizadas por terrenos úmidos, maciços/compactos, subcalcários, alcalinos ou afetados pelo cansaço (Loreti, 1988). A vasta gama de porta-enxertos, atualmente disponíveis no mercado de viveiristas internacionais, tornou indispensável o conhecimento das características bioagronômicas dos mesmos, de modo a auxiliar técnicos e fruticultores na tarefa de efetuar uma apropriada escolha deles. Portanto, mantém-se oportuno reportar a descrição dos porta-enxertos mais conhecidos ou, pelo menos, daqueles que, através da recente experimentação, forneceram os resultados mais interessantes, e o que abordaremos nesse artigo.

Termos para a indexação - enxertia, melhoramento do pessegueiro, novos cultivares, pé-franco,

\section{ROOTSTOCKS FOR CULTURE OF PEACHES OF THE THIRD MILLENIUN}

ABSTRACT - The use of rootstock always responds to modern requirements requested by a technically developed Fruticulture, started up in Italy, and general, in Europe, from the 1960's, but had assumed an important hole with the development of the industrial fruticulture.For some species, among which particularly apple and pear, this process started before and showed up more quickly, that today it has been using exclusively cloned rootstocks. For other species such as peach, the demand of new rootstock is more recently in consequence of the diffusion of this species even in areas not mentioned at all from a pedoclimatic view. The wide range of rootstock actually available in the international market of nursery became indispensable the knowledge of their bioorganic characteristics in order to help technicians and fruticulture people in the task of evaluate their proper choice. Therefore, it is appropriate to report the description of better known rootstocks or at least those which through recently trial provided the most interesting results. That what it will be discussed in this paper.

Index terms: grafting, peach breeding, seedlings, new rootstocks.

\section{INTRODUÇÃO}

O emprego de porta-enxertos sempre responde a modernas exigências pedidas por uma fruticultura tecnicamente evoluída, iniciou-se na Itália e, em geral, na Europa, a partir dos anos 60, mas assumiu importância com o desenvolvimento da fruticultura industrial. Para algumas espécies, dentre as quais particularmente a macieira e a pereira, este processo iniciou-se antes e evidenciou-se com maior rapidez, tanto que, atualmente, vêm-se se usando exclusivamente porta-enxertos clonais. Para outras espécies, como o pessegueiro, o pedido de novos portaenxertos é mais recente em conseqüência da difusão desta espécie ainda em zonas não de todo evocadas de um ponto de vista pedoclimático, o qual, a exemplo daquelas caracterizadas por terrenos úmidos, maciços/compactos, subcalcários, alcalinos ou afetados pelo cansaço (Loreti, 1988)

As vantagens conseguidas do ponto de vista técnicoeconômico com o uso de apropriados porta-enxertos, selecionados tanto sob o perfil genético quanto sanitário, junto à sua maior disponibilidade no mercado por viveiristas, fizeram com que a sua procura aumentasse não só em volume, mas também se orientasse sobre materiais com características sempre de maior qualidade.

A vasta gama de porta-enxertos, atualmente disponíveis no mercado de viveiristas internacionais, tornou indispensável o conhecimento das características bioagronômicas dos mesmos, de modo a auxiliar técnicos e fruticultores na tarefa de efetuar uma apropriada escolha deles.

Portanto, mantém-se oportuno reportar a descrição dos porta-enxertos mais conhecidos ou, pelo menos, daqueles que, através da recente experimentação, forneceram os resultados mais interessantes.

O número de porta-enxertos estudados e colocados no comércio, nos últimos vinte anos, aumentou sensivelmente, tanto que torna possível uma ampla escolha, tanto entre aqueles derivados da semente (Tab. 1), quanto entre os de origem clonal (Tab. 2). 


\section{Principais porta-enxertos de pessegueiro}

Os principais enxertos, atualmente disponíveis no mercado de viveiristas italianos e europeu, podem dividir-se fundamentalmente em três grupos, segundo a origem genética:

1. enxerto derivado de pé-franco (Prunus persica, Persica sylvestris) e suas seleções;

2. enxerto derivado da ameixeira (Prunus domestica, Prunus insititia, Prunus cerasifera) e suas seleções;

3. enxerto obtido pela hibridação entre várias espécies de Prunus (ameixeira) (P. persica, P. amygdalus, P. domestica, P. cerasifera, $P$. insititia P. davidiana, $P$. spinosa, $P$. salicina).

\section{Porta-Enxertos derivados de pé- franco e suas seleções}

\section{Pé-Franco}

Provém das sementes obtidas dos frutos, preponderantemente destinadas à indústria de transformação e, portanto, dá origem a plantas heterogêneas. Na Itália, já há alguns anos, têm-se preferido sementes obtidas da Persica sylvestris, dita também "franco-iuguslava", de origem balcânica e caracterizadas por uma menor heterogeneidade e de caroços menores. Apresentam, no entanto, uma taxa de infecção viral de $5-10 \%$.

Em geral, o pé-franco possui uma germinação de sementes variável de $60 \%$ a $80 \%$, preferindo terrenos férteis, frescos e bem drenados, nos quais desenvolve um sistema radicular extenso e profundo. Na maior parte dos cultivos enxertados, induz um bom vigor e frutificação precoce. A produtividade é média a elevada também nos terrenos áridos, embora não tolere os úmidos, pesados e calcários (máxima 6-8\% de calcário ativo).

Tais porta-enxertos vêm sendo menos utilizados nas novas implantações, cedendo espaço às mais recentes seleções que, além de serem geneticamente homogêneas, apresentam características mais interessantes (Massai et al., 1996).

\section{SELEÇÕES DO DE PÉ-FRANCO}

Entre as várias seleções de pessegueiro de pé-franco foram obtidos porta-enxertos que se diferenciam entre si por diversas características bioagronômicas e grau de suscetibilidade a diferentes doenças. Destes, alguns vêm sendo menos utilizados, como o G.F. 305; outros, ao contrário, estão difundindo-se mais, como a série P.S. da Universidade de Pisa (Loreti, 1994; Loreti e Massai, 2002) e algumas seleções recentemente lançadas na França, como o Montclar ${ }^{\circledR}$ (Grasselly, 1985).

\section{G. F. 305}

Selecionado de uma porção de sementes oriundas da Estação Experimental da Grande Ferrade (França) em 1948, é um porta-enxerto vigoroso, caracterizado por uma elevada homogeneidade no desenvolvimento das plantas no viveiro. Os caroços são pequenos (cerca de $300 / \mathrm{kg}$ ) e têm uma elevada germinação depois da estratificação a $5^{\circ} \mathrm{C}$. É compativel a toda uma variedade de pessegueiro e nectarina, sobre os quais induz um rápido desenvolvimento no viveiro e um elevado vigor a campo.

Por causa da excessiva sensibilidade ao Agrobacterium, Phythophthora, nematóides galigênero e às viroses, atualmente, vem sendo cada vez menos utilizado.

\section{Série P.S.}

Foi selecionado pelo Departamento de Cultivo e Defesa das Espécies Lenhosas "G. Scaramuzzi” da Universidade de Pisa, através da seleção de outras 1.300 sementes de pessegueiros provenientes de várias regiões italianas e de outros países.

As seleções mais interessantes, pelas suas características bioagronômicas, são P.S. A5, P.S. A6, P.S. A7 e P.S. B2, selecionadas, principalmente, pela sua homogeneidade e pelo vigor induzido neste, sendo o P.S. A6 o mais vigoroso (semelhante ao franco-eslavo), enquanto o P.S. B2, o P.S. A7 e o P.S. A5 são, respectivamente, de $10-15 \%, 15-20 \%$ e de $20-25 \%$ menos vigorosos que o P.S. A6, motivo pelo que é oportuno citar, a seguir, uma descrição sintética (Loreti e Massai, 1995; Pellegrino et al., 1997).

\section{P.S. A5}

Seleções do pessegueiro de pé-franco caracterizado por uma elevada uniformidade das sementes, as quais apresentam um bom desenvolvimento do sistema radicular e um rápido crescimento no viveiro. Os caroços são pequenos (cerca de 280/ $\mathrm{kg}$ ) e são dotados de uma elevada germinação, depois de uma estratificação a $5^{\circ} \mathrm{C}$, por cerca de 60 dias. É compatível com toda uma variedade de pessegueiro e nectarina, e mostrou um bom comportamento também com o damasqueiro, em resultados experimentais.

Nas plantas enxertadas, induz um vigor inferior a $20-25 \%$, com relação ao pé-franco comum e ao P.S. A6, um desenvolvimento muito uniforme, uma elevada produtividade $\mathrm{e}$ uma ótima eficiência produtiva. Além disso, antecipa a entrada em produção das plantas, melhorando a qualidade dos frutos, tanto no grau brix, no peso dos frutos e na coloração dos mesmos. Com relação ao pé-franco, é ligeiramente mais resistente à asfixia radicular, enquanto apresenta a mesma tolerância ao calcário e é resistente também às traqueomicoses (Cirulli et al., 2001).

É particularmente recomendado para sistemas de condução de pessegueiros em vaso retardado.

Definitivamente, pode-se afirmar que o P.S. A5 representa um ótimo porta-enxerto para o pessegueiro, preferido para os terrenos férteis e cultivos também vigorosos e/ou precoces, para densidade média a elevada de plantio.

\section{P.S. A6}

Seleção caracterizada por uma elevada uniformidade das sementes que apresentam um rápido crescimento no viveiro. Os caroços são médio-grandes (cerca $150 / \mathrm{kg}$ ), as sementes têm uma germinação elevada (acima de 95\%), depois de uma estratificação a $5^{\circ} \mathrm{C}$, por 60 dias, ou a $0^{\circ} \mathrm{C}$, por 45 dias. Propaga-se ainda por estaca lenhosa mediante aquecimento da base, com tratamento com IBA a 1.000 ppm. 
Nas plantas enxertadas, induz um vigor elevado que, em terrenos de baixa fertilidade, resultou ligeiramente inferior ao G.F. 677. Propicia uma elevada produtividade mesmo em terrenos pobres ou em ausência de irrigação, graças ao desenvolvimento do sistema radicular dotado de uma ótima ancoragem.

\section{P.S. A7}

Também esta seleção distingue-se da outra por uma elevada uniformidade das sementes, tendo mostrado um rápido crescimento no viveiro. Os caroços são médio-pequenos (cerca de $200 / \mathrm{kg}$ ), e as sementes são dotadas de elevada germinação, depois de uma estratificação a $5^{\circ} \mathrm{C}$, por cerca de 75 dias.

Como os outros francos não tolera os terrenos úmidos, pesados e mal drenados, enquanto é adequado àqueles frescos, de média ou elevada fertilidade.

Nas plantas enxertadas, induz um vigor de cerca de 15$20 \%$ inferior em relação ao franco comum, uma boa produtividade, associada a uma satisfatória qualidade dos frutos.

Para um médio vigor induzido neste, o P.S. A7 poderia permitir, na implantação, a adoção de covas ligeiramente reduzidas, mesmo em terrenos frescos, férteis e com cultivar vigorosa.

\section{P.S. B2}

Porta-enxerto caracterizado por uma elevada uniformidade das sementes que têm mostrado um bom crescimento no viveiro, mas com certa sensibilidade ao oídio. O sistema radicular é bem desenvolvido e possui ótima ancoragem. Os caroços são de dimensões médio-pequenos (cerca de 200/kg), dotados de elevada germinação, depois de uma estratificação a $5^{\circ} \mathrm{C}$, por cerca de 70 dias. Propaga-se também por estaca lenhosa mediante a técnica de aquecimento da base, com tratamento de IBA a 1.000 ppm. Com a micropropagação, os melhores resultados $(90 \%$ de enraizamento) foram obtidos com o substrato MS, para o alongamento, e WPM, para o enraizamento.

A sensibilidade à asfixia radicular e ao calcário é análoga à dos outros pessegueiros francos, enquanto se mostrou menos sensível ao replantio, provavelmente por causa da maior resistência ao Pratylencus vulnus. É adequado também aos terrenos compactos, desde que não sejam sujeitos a estagnações hídricas.

$\mathrm{Na}$ cultivar, induz um vigor médio-elevado, de qualquer modo inferior a 10-15\%, em relação ao franco-iuguslavo. Também a produtividade resultou elevada, antecipando em alguns dias a maturação dos frutos, os quais resultaram de ótima qualidade.

\section{Rubirà}

Sementes de Prunus persica obtido pela Estação Experimental da Grande Ferrade (França) e assim denominado pela cor vermelha das folhas que permitem distingui-lo facilmente no viveiro.

As plantas-matrizes são muito produtivas. Os caroços são pequenos (cerca de 330/kg), e as sementes, depois de uma estratificação de cerca de 100-110 dias, apresentam boa germinação. As sementes são muito homogêneas, vigorosas, com um rápido desenvolvimento no viveiro; são ligeiramente sensíveis ao oídio, mas resistentes aos afídios Myzus persicae.

Nas cultivar, induz um vigor inferior acerca de $15-20 \%$, com relação ao G.F. 305, uma precoce frutificação e boa produtividade. Por tais motivos, aconselha-se, para um cultivo vigoroso, que entrem mais tarde em produção, mesmo para aumentar a densidade da plantação.

Este porta-enxerto, com relação aos outros francos, mostrou menor sensibilidade ao 'Agrobacterium Meloidogyne incognita e arenaria e ao Prathylenchus vulnus', resultou suscetível aos nematóides Meloidogyne incognita e arenaria. Além disso,neste porta-enxerto, foi alguma vez assinalada, tanto na França quanto na Itália, uma mortandade de plantas que se manifesta já ao $3^{\circ}-4^{\circ}$ ano da implantação.

\section{Higama}

Porta-enxerto selecionado das sementes de Prunus persica da Estação Experimental da Grande Ferrade (França), no âmbito de uma população de sementes introduzidas do Japão, em 1960. A produtividade das plantas-matrizes é muito elevada (até $500 \mathrm{~kg}$ de caroços/ha). As sementes apresentam boa germinação, depois de uma estratificação de cerca de quatro meses.

$\mathrm{Na}$ cultivar, induz um elevado vigor adequado para o cultivo precoce, caracterizada por uma elevada produtividade.

Manifesta uma ressaltada sensibilidade à clorose e ao Agrobacterium tumefaciens, e mais ou menos tolerante aos nematóides Meloidogyne javanica e incognita.

\section{Montclar® Chanturge}

Também este porta-enxerto foi selecionado da semente de Prunus persica da Estação Experimental da Grande Ferrade (França) e apresenta características similares ao precedente pela elevada produtividade das plantas-matrizes, pela homogeneidade e pelo vigor das sementes em viveiro, e mesmo pelo elevado vigor induzido nas plantas enxertadas. Diferencia-se do Higama pela maior resistência às cloroses e às carências de $\mathrm{Fe}$ e $\mathrm{Mg}$. É o porta-enxerto mais usado pelos novos plantios de pessegueiro na França.

\section{Sibéria C}

Foi selecionado junto à Estação Experimental de Harrow (Canadá), das sementes de Prunus persica.

Os caroços são de tamanho médio $(280-300 / \mathrm{kg})$ e apresentam elevada germinação. As sementes são muito homogêneas e manifestam elevada resistência ao frio.

As plantas enxertadas nesse porta-enxerto mostraram um vigor médio ou médio-fraco e uma rápida frutificação. Também a produtividade e a eficiência produtiva são satisfatórias. Além disso, foi percebida a indução a uma leve antecipação da maturação dos frutos e menor sensibilidade das plantas ao cancro do leucostoma.

Entre as características negativas, é necessário lembrar que esse porta-enxerto resultou sensível aos excessos hídricos, aos nematóides e ao Agrobacterium tumefaciens. 


\section{PORTA-ENXERTOS DERIVADOS DAAMEIXEIRA E SUAS SELEÇÕES}

Pertence a este grupo uma vasta gama de porta-enxertos que, apesar de relativamente poucos, são aqueles que encontraram grande difusão comercial. Em geral, com relação ao franco, oferecem a vantagem de ser mais resistentes à asfixia radicular, às cloroses do calcário, aos terrenos de replantio e mesmo a algumas patogenias. Por outro lado, é preciso ressaltar que esses portaenxertos são freqüentemente mais exigentes do ponto de vista nutricional, manifestam desenvolvimento mais irregular, menor atividade polinizadora e freqüente incompatibilidade. Estas características negativas estão presentes de forma mais ou menos acentuada naqueles que podemos definir de porta-enxertos "históricos", como Akerman, Brussel, Common Plum, Common Mussel, Pershore, etc. Com o intenso trabalho de melhoramento genético, desaparecem quase completamente. Por isso, no âmbito deste grupo, serão levados em consideração os porta-enxertos mais conhecidos e aqueles que possuem características de certo interesse.

\section{San Giuliano A}

Ainda que com o termo de San Giuliano se compreenda uma população de ameixeiras referentes à espécie Prunus insititia, no âmbito desta, encontram-se genótipos que, por características morfológicas, são mais semelhantes à Prunus domestica. Trata-se de populações geneticamente complexas, provavelmente derivadas do cruzamento natural de várias espécies, motivo este da grande variedade de sementes que repercute negativamente sobre a heterogeneidade de desenvolvimento induzida, e mesmo na afinidade do porta-enxerto. Por este motivo junto à Estação Experimental de East Malling foram selecionados diversos clones (A, B, C, G, J, $\mathrm{K}$ ), entre os quais o mais interessante é aquele que encontrou maior difusão: o San Giuliano A. Este clone multiplica-se mais ou menos bem por alporquia de trincheira, mas também por estaquia no campo, dando um percentual de enraizamento satisfatório.

Manifesta bom desenvolvimento no viveiro e tem boa afinidade com as principais cultivares de pessegueiro. Pela sensibilidade aos terrenos "cloróticos", às baixas temperaturas e a diversas pragas, atualmente, tem sido pouco utilizado.

\section{San Giuliano G.F. 655/2}

Clone obtido pela Estação Experimental da Grande Ferrade (França) através de polinização livre do San Giuliano de Orléans. Propaga-se por alporquia de trincheira e por estaca lenhosa (até $80 \%$ de enraizamento); bons resultados também foram obtidos com a micropropagação.

Possui um sistema radicular mais ou menos superficial e, portanto, pouco recomendado para os terrenos áridos, bem como para os terrenos calcários, pesados, asfixiados e cansados, mas em menor medida em relação ao G.F. 1869. Provas experimentais conduzidas em terrenos de replantio com pessegueiro demonstraram que o G.F. 655/2 apresenta mortandade de plantas sensivelmente inferior à do G.F. 677 de franco.
Nas plantas enxertadas, induz vigor médio-baixo, precoce frutificação e produtividade e eficiência produtiva satisfatórias.

Por esses características, este porta-enxerto é recomendado para implantações de densidade média a elevada, também em terrenos com alta fertilidade.

A atividade polinizadora é inferior àquela do G.F. 1869 e pode-se conter sem dificuldade com o raleio químico ao longo dos ramos.

Este porta-enxerto resultou mais ou menos resistente ao Agrobacterium tumefaciens e ao Stereum purpureum.

\section{G.F.43}

Porta-enxerto clonal obtido junto à Estação Experimental da Grande Ferrade de uma semente de "Prune d'Ente" (Prunus domestica).

Propaga-se bem in vitro, enquanto, por estaca lenhosa, deu pouco resultado (cerca de $40-50 \%$ de enraizamento).

Dotado de um sistema radicular profundo e expandido, este porta-enxerto manifesta boa tolerância aos terrenos ligeiramente calcários, úmidos e pesados, e, por isso, também à asfixia radicular, substituindo, em tais condições, eficazmente, o franco.

Nas plantas enxertadas, induz elevado vigor (comparável ao franco) e ótima afinidade com todas as cultivares experimentadas. Contudo, foi percebida uma frutificação mais lenta, uma maturação dos frutos mais ou menos gradual e uma eficiência produtiva das árvores freqüentemente insatisfatória.

Em relação aos outros clones de ameixeira (G.F 1869 e G. F. $655 / 2$ ), é aquele que manifesta a menor atividade polinizadora, o que o torna muito limitado.

Este porta-enxerto manifestou ser relativamente sensível ao replantio e mais ou menos suscetível ao "chlorotic leaf spot" (CLSV), o que pode determinar a incompatibilidade com o enxerto. É indispensável, portanto, usar material isento de vírus.

\section{Tetra}

É um Prunus domestica obtida pela livre polinização da cultivar 'Regina Claudia Verde', junto à seção de pomologia do Instituto Experimental para a Fruticultura de Roma. Propaga-se facilmente tanto in vitro quanto por estaca lenhosa, com auxílio de IBA a $2.000 \mathrm{ppm}$.

As plantas em viveiro são vigorosas, homogêneas e facilmente enxertáveis tanto por meio de gema, quanto por garfagem. O sistema radicular, uniformemente distribuído, garante ótima ancoragem; adapta-se a todo tipo de terreno e é resistente tanto ao calcário, na mesma medida do G.F. 677, quanto à asfixia radical.

É um porta-enxerto perfeitamente compatível ao pessegueiro, nectarina, damasqueiro e ameixeira; provas experimentais demonstram, também, uma perfeita afinidade com a amendoeira, depois de quatro anos do enxerto, e um retardamento na floração de 5-6 dias, com relação ao G.F. 677. Não apresenta atividade polinizadora.

No pessegueiro e na nectarina, induz um desenvolvimento da planta de $15-20 \%$ menor que o G.F. 677 ; no damasqueiro e na ameixeira, induz reduções similares ao Mirabolano 29C. Nos frutos do pessegueiro e nectarina, melhora a coloração da película dos frutos, especialmente nas cultivares de maturação precoce, e uma 
antecipação do amadurecimento de 3-4 dias, sendo a eficiência produtiva igual à do G.F. 677 ou à de um pessegueiro de péfranco.

Este porta-enxerto é tolerante aos nematóides gálicos (Meloidogyne ssp); além disso, as primeiras investigações experimentais indicam que é resistente à Phytophtora cinnamoni e tolerante à Armillaria mellea.

\section{Penta}

Como o anterior, é uma Prunus domestica obtida pela polinização livre da cultivar 'Imperiai Epineuse' junto à seção de Pomologia do Instituto Experimental para a Fruticultura de Roma. Apresenta as mesmas caracterísitcas do Tetra, mas difere deste pela capacidade de induzir um vigor ligeiramente superior, similar ao G.F. 677 , e por não antecipar a maturação dos frutos. Como o Tetra, é tolerante ao Meloidogyne ssp e resistente ao ,outonal, mas, atualmente, tem sido propagado exclusivamente por micropropagação.

Porta-enxerto muito vigoroso (superior ao franco de 10$15 \%$ ), é provisionado por um complexo de raízes dotado de ótima ancoragem, que se adapta a terrenos pouco férteis e áridos, desde que sejam permeáveis. Apresenta elevada resistência à clorose, fornecendo bons resultados produtivos, também em terrenos com calcário ativo superior a 8-10\%. Graças ao seu elevado vigor, consegue superar muito bem os problemas ligados ao replantio. Pelas suas características acima citadas e pela boa afinidade mostrada com todas as cultivares de pessegueiro e nectarina cultivadas comercialmente, é o porta-enxerto que, na Itália e em outros países da bacia do mediterrâneo, encontrou a maior difusão depois do franco e as suas seleções.

Apesar destas considerações, não podemos esquecer, porém, os numerosos defeitos que ele apresenta, entre os quais o excessivo vigor induzido às plantas enxertadas, que, além de retardar a entrada em frutificação das mesmas, influencia negativamente na produtividade (freqüentemente inferior à do franco) e nas características qualitativas dos frutos (menor peso e coloração dos frutos). Estes defeitos tendem a desaparecer quando as plantas alcançarem o equilíbrio vegetativo-produtivo e entrarem em plena produção. Por esses motivos, este porta-enxerto é desaconselhável em terrenos muito férteis e para implementações em alta densidade.

Outros inconvenientes são representados pelo fato de que o G.F. 677 não tolera os terrenos argiloso-limbosos e sujeitos a estagnação hídrica, enquanto é sensível à asfixia radicular. Além de sua suscetibilidade à Armillaria mellea, ao Agrobacterium tumefaciens, à Phytosphora cactorum e ao Stereum purpereum resultar mais ou menos elevada, enquanto intermediária entre a da amendoeira e a do pessegueiro, e a sensibilidade ao Verticillium alboatrum.

\section{Série I.S.}

Trata-se de uma série de clones que derivam de sementes obtidas pela polinização livre do híbrido pessegueiro $\mathrm{x}$ amendoeira G.F. 577, selecionados pelo Departamento de Cultivo e Defesa das Espécies Lenhosas “G. Scaramuzzi”, da Universidade de Pisa (Loreti e Massai, 1994).
Apresentam muitas características comuns entre si e o G.F. 677 , mas diferenciam-se especialmente pelo grau de vigor induzido nestes. Os clones mais interessantes são, em ordem crescente de vigor, Sírio, Castore e Polluce (Massai et al., 2002).

\section{Sirio}

Clone selecionado com a sigla I.S. $5 / 22$, é dotado de escasso poder rizógeno/rizógono, dificilmente propaga-se mediante mergulia de cepa e alporquia, enquanto forneceu discretos resultados com a multiplicação por estaca lenhosa em pleno campo, com prévio tratamento com IBA a $2.000 \mathrm{ppm}$.

Tais resultados não foram, entretanto, confirmados quando as estacas, tratadas com ISA nas mesmas concentrações, foram postas para enraizamento com a técnica do aquecimento da base. Propaga-se bem por micropropagação.

Apresenta um bom sistema radicular, adapta-se aos terrenos férteis e permeáveis, onde obtém um bom controle do desenvolvimento vegetativo, dando lugar a plantas bem equilibradas. Tem boa resistência às cloroses, resultando ligeiramente inferior ao G.F. 677.

Plantas enxertadas no Sírio mostraram um vigor reduzido de cerca de $40 \%$, antecipação na frutificação, elevada eficiência produtiva, maior peso e melhor coloração dos frutos.

É compatível com as principais cultivares de pessegueiro e nectarina comercialmente cultivadas.

Pelo reduzido vigor e pela resistência ao calcário, é recomendado para constituir implantações de alta densidades, ainda em terrenos férteis e "cloróticos", onde não é possível adotar o G.F. 677, com o qual se obtêm plantas muito vigorosas que requerem, portanto, covas de implantação mais largas.

\section{Castore}

Clone selecionado com a sigla I.S. 5/19, é dotado de baixo poder de enraizamento, dando resultados insatisfatórios com a propagação por estaca (inferior a $50 \%$ de enraizamento) e negativos com mergulia. Bons resultados foram obtidos com a micropropagação.

Prefere os terrenos férteis e frescos, não sendo recomendado para terrenos pesados e sujeitos a estagnação hídrica, nos quais é necessário efetuar boa drenagem.

Este porta-enxerto propicia um bom controle do vigor, que com relação ao G.F. 677 resultou inferior em cerca de 30\%.

Induz boa produtividade e elevada eficiência produtiva, calculada como produção acumulada, tanto com a seção do tronco, quanto com a da madeira de poda verde e de inverno.

É positiva a influência sobre a qualidade dos frutos, mostrando um elevado conteúdo em sólidos solúveis, boa relação açúcares/ácidos, e intensa coloração vermelha. Além disso, adaptase bem ainda em condições de terreno pouco fértil, onde mostrou bom crescimento vegetativo e eficiência produtiva similar à do G.F. 677.

Portanto, pode-se afirmar que este porta-enxerto representa uma alternativa ao G.F. 677 e ao pessegueiro franco em terrenos muito férteis, onde o elevado desenvolvimento induzido por estes porta-enxertos não permite aumentar a densidade de plantio e a adoção de formas de condução adequadas ao solo. 
Polluce

Selecionado com a sigla I.S. 5/8, também este clone, pelo limitado poder de enraizamento, dificilmente se propaga por estaca lenhosa, uma vez que, das várias provas feitas com a técnica de aquecimento da base e tratamentos com IBA em várias concentrações, foi obtido enraizamento inferior a 30\%. Resultados negativos têm-se obtido, com a mergulia, enquanto com a micropropagação, tanto a proliferação quanto o enraizamento são satisfatórias.

Analogamente aos outros híbridos pessegueiro $\mathrm{x}$ amendoeira, não é recomendado para os terrenos úmidos, pesados e mal drenados, enquanto é adequado àqueles frescos de média ou elevada fertilidade.

Induz neste um vigor inferior acerca de $20 \%$ em relação ao G.F. 677, boa produtividade e elevada eficiência produtiva.

Também as características qualitativas dos frutos são influenciadas positivamente, determinando boa coloração dos frutos e mais elevada relação açúcares/ácidos.

Definitivamente, este porta-enxerto, pelo menor vigor, em relação ao G.F. 677, permite desenvolver precocemente bom equilíbrio vegetativo das plantas, que mostraram boa produtividade, maior eficiência produtiva e ótimas características qualitativas dos frutos.

Este porta-enxerto, ainda, poderia representar, portanto, uma válida alternativa ao G.F. 677, especialmente em terrenos dotados de médio-elevada fertilidade onde, em relação a este último porta-enxerto, poderia permitir a redução das covas na implantação e das intervenções de podas, efetuadas preponderantemente na parte baixa da planta.

Em terrenos dotados de escassa fertilidade, induziu sensível redução do crescimento, porém mantendo bons níveis de produtividade.

\section{Hansen 2168 e Hansen 536}

São clones selecionados pela Universidade da Califórnia (USA), no âmbito de uma população de sementes obtidas pelo cruzamento do pessegueiro $\mathrm{x}$ amendoeira.

Propagam-se por estaca lenhosa no período outonal, mas deram bons resultados com a micropropagação.

Porta-enxertos de notável vigor, superiores àquele do G.F. 677, induzem produtividade análoga à do franco e mesmo à do G.F. 677. Ambos apresentam elevada resistência ao calcário e são imunes aos nematóides Meloidogyne incognita, variedade "acrita" e Meloidogyne javanica. Além disso, o Hansen 2168 é moderadamente tolerante a Phythophthora. Ambos resultam, ao contrário, sensíveis ao Agrobacterium tumefaciens que, pelas primeiras observações, parece atacar mais o Hansen 536.

A recente introdução, na Itália, destes enxertos, não permite poder formular ainda uma recomendação definitiva sobre o seu comportamento, ainda que, pelas primeiras observações, não pareçam ser muito promissores.

\section{Adafuel}

É híbrido de amendoeira x pessegueiro, selecionado junto à Estação Experimental Aula Dei de Saragoza (Espanha), de uma população de sementes obtidas pela livre polinização do cultivo de amendoeira "Marcona". Propaga-se facilmente por estaca lenhosa, dando percentuais de enraizamento superiores ao G.F. 677. As plantas-matrizes são vigorosas, com um crescimento semiereto. As gemas manifestam um elevado dominância apical, com pouquíssimos ramos antecipados, permitindo,assim, fácil execução da enxertia no viveiro. É um porta-enxerto muito vigoroso, adequado para terrenos calcários, mesmo que leves e bem drenados. Mostrou boa afinidade com as mais comuns cultivares de pessegueiro e de amendoeira difundidas comercialmente, induzindo às plantas desenvolvimento e eficiência produtiva similares à do G.F. 677 .

Estudos efetuados em viveiro, colocaram em evidência que o Adafuel é resistente à Sphaeroteca pannosa, Tranzschelia pruni-spinosae e ao Corineum beijerinckii, é muito sensível ao Agrobacterium tumefaciens e aos nematóides Meloidogyne ssp.

\section{Adarcias}

Como o anterior é um híbrido de amendoeira $\mathrm{x}$ pessegueiro, selecionado de uma população de sementes de polinização livre, junto à Estação Experimental Aula Dei de Saragoza (Espanha).

Propaga-se facilmente por estaca lenhosa, mas também por micropropagação. As plantas-matrizes são de médio vigor e apresentam porte elevado. Adapta-se bem aos terrenos calcários, desde que sejam escolhidos e bem drenados.

OAdárcias induz um vigor inferior, com relação ao Adafuel e ao G.F. 677, mas maior eficiência produtiva e melhor qualidade dos frutos. Resulta, portanto, recomendado para reduzir o excessivo desenvolvimento das plantas e, conseqüentemente, os custos para a sua manutenção. Permite, além disso, aumentar a densidade de plantio.

Mostrou boa afinidade com numerosas cultivares de pessegueiro e nectarina, e com o cultivo de ameixeiras tipo japonesas, até agora estudadas.

Provas feitas em viveiro evidenciaram que o Adarcias é resistente ao Corineum beijerinckii e ao Tranzschelia prunispinosae.

\section{Nemaguard e Nemared}

Entre os porta-enxertos selecionados pela resistência aos nematóides, o Nemaguard é, sem dúvida, aquele que encontrou maior difusão tanto ao norte, quanto ao sul da América. Trata-se de um suposto híbrido natural entre Prunus persica $x$ Prunus davidiana, selecionado pela USDA. em Fort Walley, na Geórgia (USA).

Os carroços são mais ou menos pequenos $(270-300 \mathrm{Kg})$, caracterizados por elevada germinação, quando submetidos à estratificação/escalificação a $5^{\circ} \mathrm{C}$, por cerca de quatro meses. Também multiplica-se bem por mergulia. Estas sementes são mais ou menos homogêneas e apresentam bom crescimento no viveiro.

Mostrou boa afinidade com todos as cultivares de pessegueiro e nectarina estudadas.

As plantas enxertadas neste porta-enxerto manifestaram bom vigor, mas a produtividade resultou, ao menos na Itália, inferior àquelas obtidas com outros enxertos francos. 
Apresenta boa resistência ao Meloidogyne javanica e arenaria, embora, recentemente, tenha sido reconhecido que novo biótipo de Meloidogyne javanica passar proliferar sobre as raízes do Nemaguard. A resistência ao Meloidogyne incognita variedade "ácrita" é heterozigótica, de modo que $25 \%$ das sementes podem apresentar lesões radiculares.

Resultou sensível aos danos causados pelo frio, ao Pratylencus vulnus, ao apodrecimento radicular, ao Vertilicium, à clorose e à asfixia radicular. Dentre os porta-enxertos até aqui descritos, é aquele que mostrou ser o mais tolerante ao Agrobacterium tumefaciens.

Este porta-enxerto pode ser utilizado em replantio, dando lugar a plantas mais vigorosas do que o franco comum.

Pelos numerosos defeitos que este porta-enxerto manifesta, pode-se validar seu uso, simplesmente, em terrenos que apresentam fortes infestações de nematóides gálicos e encontraram pequena difusão, tanto na Itália quanto nos outros países europeus.

O Nemared, ao contrário, foi selecionado pela USDA, em Fresno, na Califórnia, de plantas provenientes do cruzamento da terceira geração de Nemaguard $\mathrm{x}$ sementes de pessegueiro de folha vermelha. Este porta-enxerto, em relação ao Nemaguard, induz vigor ligeiramente superior e maior tolerância ao Meloidogyne incognita e javanica. As folhas são de cor vermelha, o que deixa facilmente distinguível as plantas no viveiro. As sementes são muito uniformes e formam menor número de ramos antecipados, que facilitam as operações de enxertia.

\section{Guardian® BY520}

Posto em comércio em 1993, conjuntamente pela USDA e pela Clemson University, Guardian é um porta-enxerto que apresenta muitas características similares ao Nemaguard.

As principais diferenças são representadas por menor germinação dos caroços, menor resistência aos nematóides gálicos (Meloidogyne incognita, Meloidogyne javanica e Meloidogyne arenaria), maior tolerância ao Mesocriconema xenoplax, ao "cancro bactérico" (batterico) e ao Peach tree short life (Reighard et al., 1997; Beckman et al., 1997a). Estas últimas características fizeram-no popular no sul dos Estados Unidos.

\section{Cadaman ${ }^{\circledR}$ Avimag}

É um porta-enxerto obtido na Hungria, por hibridação interespecífica de Prunus persica x Prunus davidiana e introduzido na França pela INRA. Propaga-se facilmente por estaca herbácea ou semilenhosa.

Nas plantas enxertadas, induz um vigor similar ao do G.F. 677, que, em todo caso, tende a diminuir a partir dos 4-5 anos de idade. Também a produtividade é equivalente ou superior à das plantas enxertadas pelo G.F. 677, com relação ao qual, porém, antecipa ligeiramente a frutificação, dando frutos de maior tamanho. Foi revelado que, entretanto, com relação ao G.F. 677 e ao Julior Ferdor, retarda a maturação dos frutos, respectivamente, de 1-2 ou 3-5 dias.

Manifestou boa resistência aos terrenos asfixiados e é tolerante à clorose e ao replantio.
Além disso, é resistente ao Meloidogyne incognita, mas sensível ao Meloidogyne javanica.

Definitivamente, o Cadaman ${ }^{\circledR}$, em relação ao G.F. 677 , apresenta diversas características positivas, dentre as quais: rápida formação da planta, bom comportamento no replantio, boa tolerância à clorose e, especialmente, à asfixia radicular. Pelo elevado vigor induzido nas plantas enxertadas, não se presta para sistemas em alta densidade, que são aquelas adotadas pelo G.F. 677.

\section{Barrier 1}

Híbrido interespecífico de Prunus davidiana x Prunus persica, foi selecionado pelo ex-Instituto para a Propagação das Espécies Lenhosas de Florença.

Este porta-enxerto também induz vigor igual ou superior ao do G.F. 677, com um sistema radicular muito expandido e profundo, dotado de ótima ancoragem.

Propaga-se bem tanto por estaca lenhosa, no período outonal, quanto mediante a técnica de micropropagação. Adapta-se bem a vários tipos de terreno, nos "cloróticos", asfixiados e em replantio. Manifestou boa resistência ainda aos nematóides gálicos. Além de induzir produtividade e peso dos frutos superiores ao G.F. 677.

Portanto, este porta-enxerto pode ser empregado em terrenos de replantio e onde, por problemas de asfixia radicular, não é possível utilizar os outros híbridos pessegueiro $\mathrm{x}$ amendoeira.

\section{Mr.S. 2/5 e Mr.S.2/8}

Estes porta-enxertos foram selecionados pelo Departamento de Cultivo e Defesa das Espécies Lenhosas da Universidade de Pisa, no âmbito de uma população de Mirabolano de polinização livre. A origem do Mr.S. 2/5 é incerta; trata-se de um híbrido pentaplóide $(2 \mathrm{n}=40)$ espontâneo, provavelmente referente ao Prunus cerasifera $x$ Prunus spinosa.

Os dois clones apresentam muitas características em comum, como: a fácil propagação por alporquia, por estaca lenhosa em campo e micropropagação, método este com o qual ambos os clones são propagados comercialmente. Para obter elevado desenvolvimento das plantas enxertadas nas gemas (laterais), com relação aos outros enxertos, resultou importante antecipar a execução dos enxertos de 10-15 dias, enquanto as estacas cessam de vegetar mais ou menos precocemente; caso contrário, o percentual de desenvolvimento pode ser sensivelmente comprometido. Além disso, as sementes mostraram ser sensíveis à ferrugem. A afinidade resultou ótima com o cultivo do pessegueiro e nectarina até o momento estudados; o vigor induzidos às plantas enxertadas resultou de 10$15 \%$ inferior ao franco e de $25-30 \%$ inferior ao G.F. 677 ; a atividade polinizadora é muito modesta.

Ambos os porta-enxertos manifestaram induzir elevada produtividade e eficiência produtiva, ótimo tamanho dos frutos e intensa coloração destes que, nas plantas enxertadas com Mr.S. 2/ 5 , mostraram antecipar a maturação em alguns dias.

As diferenças encontradas entre os dois clones consistem, especialmente, no fato de que o Mr.S. 2/5 manifestou maior resistência ao Agrobacterium tumefaciens (Zoina e Raio, 1999), ao calcário e à asfixia radicular, podendo vegetar bem em prolongadas condições de reduzida disponibilidade de oxigênio no solo. Isto parece ligado, além da resistência genética, também à 
possibilidade de emitir facilmente raízes temporárias do colo, que vão substituir aquelas inferiores, eventualmente prejudicadas.

Enfim, este porta-enxerto manifestou bom comportamento ao ser utilizado em terrenos de replantio, enquanto consegue induzir boa atividade vegetativa, ainda nos primeiros anos depois da implantação.

\section{Myran® Yumir}

É um híbrido interespecífico de Prunus cerasiferax Prunus salicina obtido junto à Estação Experimental da Grande Ferrade, em 1950. Propaga-se bem por estaca lenhosa e semilenhosa, no outono.

Todas as cultivares de pessegueiro $\mathrm{x}$ amendoeira enxertadas neste pota-enxerto mostraram boa afinidade, aos quais confere um vigor médio-elevado, principalmente durante os primeiros anos de vegetação. $O$ grau de vigor definitivo, nas plantas em plena produção, é superior ao Damasco 1869, mas inferior ao G.F. 305.

Também a produtividade das plantas, a partir dos 4-5 anos, resultou superior a ao Damasco 1869, mas inferior ao G.F. 305.

A época de maturação, o peso e a coloração dos frutos é similar àquela obtida por plantas enxertadas pelo franco comum.

Este porta-enxerto não é polinizador; é sensível à clorose calcária, mas tolerante à asfixia radicular, às infestações de Armillaria mellea e mesmo aos nematóides do gênero Meloidogyne.

\section{Citation ${ }^{\circledR}$ Zaipime}

Foi obtido pela Floyd Zaiger, em Modesto, Califórnia (USA), pela polinização livre da ameixeira 'Red Beaut'. Trata-se de um híbrido interespecífico de Prunus salicina x Prunus persica.

Porta-enxerto clonal de folhas vermelhas, propaga-se facilmente por estaca herbácea ou lenhosa, e mesmo por micropropagação. Por recentes provas conduzidas em diversas áreas da cultura do pessegueiro na Itália, parece estar em desacordo com o pessegueiro, senão com a cultivar 'Sprincrest'.

Isto poderia ser o motivo do menor vigor induzido nas plantas enxertadas com tal porta-enxerto, resultado inferior a 40-50\% em relação ao franco, e de 15\% em relação ao G.F. 655/2.

Induz, além disso, uma precoce maturidade da madeira e antecipada queda das folhas.

Não possui atividade polinizadora, parece resistente à asfixia radicular e tolerante a podridões. Além disso, mostrou incompatibilidade com a cultivar 'Mirabelle'.

Pelas vistosas flores vermelhas, geralmente gimnospermas e pela coloração vermelha das folhas, é também utilizado como planta ornamental.

É um porta-enxerto polivalente que forneceu bons resultados com a ameixeira.

\section{Isthara ${ }^{\circledR}$ Ferciana}

É um híbrido interespecífico complexo-(Prunus cerasifera $x$ Prunus salicina) $x$ (Prunus cerasifera $x$ Prunus persica) selecionado junto ao INRA de Bordeaux. É um porta-enxerto polivalente, que pode ser usado para o pessegueiro, damasqueiro e a ameixeira, e que induz um vigor médio. Com o pessegueiro, mostrou a boa afinidade e reduzida atitude polinizadora. Adapta- se bem às diversas situações pedoclimáticas, porém demonstra ser sensível tanto aos terrenos asfixiados quanto aos "cloróticos". Nos terrenos frescos e férteis, dá os melhores resultados, contribuindo para reduzir o tamanho das plantas e melhorar a quantidade de frutos, principalmente nos cultivos precoces.

Este porta-enxerto, por uma plurianual experimentação, ainda agora em curso, em várias regiões de cultura do pessegueiro italiano, forneceu resultados muito interessantes tanto sobre o perfil produtivo quanto qualitativo dos frutos. Além disso, é oportuno evidenciar que a ação exercida por este porta-enxerto na época de floração e de maturação, na cultivar 'Suncrest', foi retardada de 4-7 dias.

\section{Julior ${ }^{\circledR}$ Ferdor}

É um híbrido interespecífico de Prunus insistitia x Prunus domestica, selecionado pelo INRA de Bordeaux. Mostrou ter afinidade com o pessegueiro, a ameixeira e o damasqueiro. Propaga-se bem por estaca lenhosa ou pela micropropagação. É um porta-enxerto de médio vigor, superior ao G.F. 655-2, em grau de conter o desenvolvimento das plantas, também em terrenos muito férteis. Apresenta boa resistência à asfixia radicular, mas é sensível à clorose calcária, já a um $\mathrm{pH}$ 8.2. Mostrou elevada heterogeneidade de comportamento nos diversos ambientes pedoclimáticos, lenta frutificação das plantas e elevada atividade polinizadora, logo nos primeiros anos de implantação.

\section{Jaspi® Fereley}

Enxerto obtido pelo INRA de um cruzamento de Prunus salicina $x$ Prunus spinosa, é um porta-enxerto polivalente, mais indicado para o damasqueiro e a ameixeira, que para o pessegueiro. Induz um vigor inferior a $20 \%$ com relação ao franco. Porém, adapta-se aos terrenos difíceis, graças à resistência mostrada para aqueles asfixiados, calcários e de replantio. Apesar de ter mostrando estes caracteres interessantes, Jaspi-Fereley é um porta-enxerto desaconselhável pelos graves problemas de incompatibilidade com o cultivo do pessegueiro.

\section{Novos porta-enxertos}

O intenso trabalho de melhoramento genético dos portaenxertos das plantas frutíferas, empreendidos nestes últimos anos por várias instituições científicas e/ou por viveiristas privados a nível mundial, aumentou sensivelmente o número das entradas que poderão, logo, tornar-se disponíveis para viveiristas e fruticultores.

Ainda para o pessegueiro, os porta-enxertos que foram recentemente assinalados são mais ou menos numerosos, dos quais uma parte está em fase avançada de seleção, enquanto de outros não se conhece nem mesmo o seu comportamento.

Entre as novidades, alguns porta-enxertos de origem espanhola parecem levantar certo interesse. Tratam-se de clones de amendoeira x pessegueiro Monegro, Garnem e Felinem, da Unidade de Fruticultura SAI-DGA de Saragoza, obtidos pelo cruzamento da Amendoeira Garfi x Nemared. Estes enxertos, de folha vermelha, apresentam bom enraizamento, elevado vigor (superior ao G.F. 677), resistência ao calcário e aos nematóides gálicos 
(Gonzales Berbegal et al., 2002; Iglesias et al., 2002; Weibel et al., 2002).

No Centro de Investigação e Desenvolvimento Agroalimentício da Múrcia, ao contrário, foi recentemente licenciado o Mayor, híbrido de amoreira x pessegueiro de elevado vigor, indicado para terrenos pobres, calcários e áridos (Rodriguez Navarro, 2002; Rodriguez Navarro e Carillo Navarro, 2002), mas muito suscetível aos nematóides gálicos (Pinochet et al., 2002).

Da Romênia foi remarcada uma série de porta-enxertos selecionados, quase todos da Prunus persica, que se diferenciam eles, fundamentalmente, pelo grau de vigor induzido nestes como o Tomis 1, o Tomis 79, o T 16, o P 1, o Oradea 1, o De Baltic (Indreias et al., 2002; Baciu et al., 2002). Também junto à Krymsk Breeding Station de Krasnodar (Rússia), foram selecionados da Prunus spp uma série de porta-enxertos caracterizados por um diferente grau de vigor, fácil propagação por estaca lenhosa e boa adaptabilidade a várias condições pedoclimáticas, como o Adaptil e o Misofer (Eremin e Eremin, 2002). Além disso, da mesma Estação Experimental, as seleções VVA-1, VSV-1 e Kubah 86 foram licenciadas com o nome Krymsk ${ }^{\circledR}$ 1, Krymsk ${ }^{\circledR} 2$ e Krymsk ${ }^{\circledR} 86$, respectivamente. Também na China, foi iniciada a seleção de porta-enxertos pela resitência a várias doenças em diversas zonas geográficas (Wang et al., 2002), sem porém terem sido licenciadas, até agora, em outros países. O melhoramento genético dos porta-enxertos do pessegueiro para o controle do vigor foi, recentemente, examinado também na Califórnia, tanto através da polinização livre do Prunus bessey $x$ Prunus Salicina, quanto mediante o cruzamento da Prunus Salicina x Prunus dulcis (DeJong, 2002). Na Carolina do Sul, ao contrário, foi posta notável atenção à seleção de porta-enxertos resistentes à síndrome do 'Peach tree short life' (P.T.S.L.), que permanece ainda um dos problemas não completamente resolvidos pela cultura do pêssego das regiões do sudeste dos Estados Unidos (Reighard et al., 2002).

Destes e outros porta-enxertos expostos recentemente à atenção dos pesquisadores, não se dispõe, porém, de suficientes informações. Mantém-se, portanto, oportuno reportar só um elenco com relativas notas bibliográficas e, onde disponíveis, os principais objetivos de seleção (Tab. 3).

\section{Considerações finais}

Pelo objetivo até aqui examinado, resulta evidente que o panorama dos porta-enxertos do pessegueiro, atualmente disponíveis, aumentou sensivelmente, oferecendo variadas possibilidades de escolha em relação às condições pedoclimáticas, ao controle do vigor, à resistência aos estresses bióticos e abióticos, e mesmo às características técnico-culturais, que se pretendem adotar para o cultivo do pessegueiro (Loreti e Massai, 2006).

De fato, ao lado dos porta-enxertos tradicionais, dentre os quais o franco e as suas seleções, os quais melhoraram entre este sensivelmente, principalmente o caráter homogeneidade de desenvolvimento, novos interessantes estudos foram selecionados no âmbito da ameixeira, que permitem maior adequação às condições pedológicas e uma menor suscetibilidade ligada a algumas doenças. Mas, onde o melhoramento genético consentiu concernir os maiores progressos, foi na hibridação interespecífica, a qual permitiu obter porta-enxertos com características de recomendação, que permitiram resolver graves problemas, até agora restritivos da expansão da cultura do pessegueiro. É evidente que a ampliação da gama de porta-enxertos, se, por um lado, enriqueceu o panorama viveirístico, por outro, tornou mais complexa a escolha, que pressupõe um exato conhecimento do comportamento bioagronômico de cada um desses. Apenas através de tal conhecimento é possível oferecer a garantia necessária a fim de que os fruticultores possam efetuar uma escolha apropriada e responsável.

TABELA 1 - Principais porta-enxertos de semente atualmente disponíveis para o pessegueiro.

\begin{tabular}{|c|c|c|}
\hline Seedling & Country & Genetic origin \\
\hline Standard seedling & $\begin{array}{l}\text { From canning cvv or other cvv } \\
\text { cultivated in different countries }\end{array}$ & Prumus persica \\
\hline Slavic seedling & Ex Jugoslavia -Balcanic area & Persica sylvestris \\
\hline $\begin{array}{l}\text { G.F. 305, Rubirà , Higama, Montclar - } \\
\text { Chanturge }\end{array}$ & INRA - France & Prunus persica \\
\hline P.S.A5, A6, A7, B2 & DCDSL - Pisa - Italy & Prunus persica \\
\hline Guardian Brand BY520-9 & $\begin{array}{l}\text { Dept. Hortic. Clemson Univ., S. } \\
\text { Carolina (USA) }\end{array}$ & Prunus persica \\
\hline Siberian C & Fyn Sto Harnow Ontarin (Cande) & $P_{\text {rumus navica }}$ \\
\hline Harrow Blood & 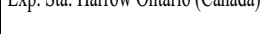 & romins persica \\
\hline Nemaguard & \multirow{2}{*}{ USDA - Georgia (USA) } & P. persica $x$ P. davidiana \\
\hline Nemared & & $\begin{array}{c}\text { P. persicax (P. persica } x \text {. } \\
\text { davidiana) }\end{array}$ \\
\hline
\end{tabular}

TABELA 2 - Principais porta-enxertos clonais atualmente disponíveis para o pessegueiro.

\begin{tabular}{|c|c|c|}
\hline Rootstock & Country & Genetic origin \\
\hline $\begin{array}{ll}\text { G.F.6.677 } \\
\end{array}$ & INRA - France & P. persica $\times$ P. amygdalus \\
\hline Titan & \multirow{2}{*}{ Univ. California - USA } & P. persica $x$ P. amygdalus \\
\hline Hansen 2168 , Hansen 536 & & P. amygdalus $x$ P. persica \\
\hline $\begin{array}{l}\text { Felinem* (GxN22), Garnem* (GxN15), } \\
\text { Monegro* (GxN9) }\end{array}$ & SIA - DGA, Zaragoza, Spain & P. amygdalus $\times$ P. persica \\
\hline Barrier 1 & IPSL-CNR- Florence, Italy & P. davidiana $\times$ P. persica \\
\hline Cadaman -Avimag & $\begin{array}{l}\text { INRA - France; Inst. Frut. } \\
\text { Budapest - Ungheria }\end{array}$ & P. persica $x$ P. davidiana \\
\hline Adafuel, Adarcias & $\begin{array}{l}\text { Exp. Stat. Aula Dei Zaragoza - } \\
\text { Spagna }\end{array}$ & P. persica $x$ P. amygdalus \\
\hline Sirio, Castore, Polluce & \multirow{2}{*}{ DCDSL - Pisa - Italy } & P. persica $x$ P.amygdalus \\
\hline Mr.S.2/5, Mr.S.2/8 & & Ibrido nat. di P. cerasifera \\
\hline Penta, Tetra & Ist. Sper. Frut. - Roma - Italy & P. domestica \\
\hline G.F.1869 & \multirow{8}{*}{ INRA - France } & P. domestica x P. spinosa \\
\hline G.F.43 & & P. domestica \\
\hline G.F.655/2 & & P. insititia \\
\hline Julior -Ferdor & & P. insititia $x$ P. domestica \\
\hline Ishtara -Ferciana & & $\begin{array}{l}\text { (P. cerasifera } x \text { P. salicina) } x \\
(\text { P. cerasifera } x \text { P. persica })\end{array}$ \\
\hline Myran -Yumir & & $\begin{array}{c}\text { (P. cerasifera } x \text { P. salicina }) x \\
\text { P. persica }\end{array}$ \\
\hline Myrabi & & Ibrido di P. cerasifera \\
\hline Jaspi -Fereley & & P. salicina $x$ P. spinosa \\
\hline Adesoto 101, Montizo, Montpol & $\begin{array}{l}\text { Exp. Stat. Aula Dei Zaragoza - } \\
\text { Spain }\end{array}$ & P. insititia \\
\hline Citation -Zaipime & Univ. California - USA & P. persica P. salicina \\
\hline
\end{tabular}


TABELA 3 - Porta-enxertos de pessegueiro obtidos pelo programa de melhoramento genético conduzido por alguns países Europeus e da América do Norte.

\begin{tabular}{|c|c|c|}
\hline Rootstock candidate & Country of origin & Genetic origin \\
\hline Mayor & \multirow[t]{2}{*}{ CIDA, Murcia, Spagna. } & $\begin{array}{c}\text { P. persica } x \text { P. } \\
\text { amygdalus }\end{array}$ \\
\hline PollizoV4 & & P. insititia \\
\hline Hiawatha & \multirow{3}{*}{$\begin{array}{l}\text { Dept. Pomology, Fresno, California } \\
\text { (USA) }\end{array}$} & P. besseyix P. salicina. \\
\hline K-146-43, K-146-44, P-30-135 & & P. salicina $x$ P. persica \\
\hline K-119-50 & & P. salicina $\times$ P. dulcis \\
\hline $\begin{array}{l}\text { VSV-1, VVA-1, Druzba, } \\
\text { Kuban-86, Evrica }\end{array}$ & Krymsk Breed. Stat., Krasnodar, Russia & Prunus hybrids \\
\hline PG1, PG3 & Università di Craiova, Romania & P. persica \\
\hline T16, Tomis 1, Tomis 79 & Fruit Res. Stat. Constanta, Romania & P. persica \\
\hline Oradea 1, De Balc & Fruit Res. Stat. Bihor, Romania & P. persica \\
\hline P1s & \multirow{3}{*}{$\begin{array}{l}\text { Fruit Res. Inst. Pitesti-Maracineni, } \\
\text { Romania }\end{array}$} & Prunus persica. \\
\hline Adaptabil & & Prunus besseyi \\
\hline Miroper & & P. cersifera $x$ P. persica \\
\hline
\end{tabular}

\section{REFERÊNCIAS}

BACIU, A., GODEANU, I.; SINA, C. Researches regarding new generative rootstocks for peach tree [Prunus persica $(\mathrm{L}) \mathrm{Batsch}$ ]. In: INTERNATIONAL SYMPOSIUM ON ROOTSTOCKS FOR DECIDUOUS FRUIT TREE SPECIES, 1., 2002, Zaragoza. Proceedings...

BECKMAN, T.G.; REIGHARD, G.L.; OKIE, W.R.; NYCZEPIR,A.P.; ZEHR, E.I.; NEWALL, W.C. History, current status and future potential of Guardian TM peach rootstock. Acta Horticulturae, Wageningen, v.451.n.1, p.251-258. $1977^{\mathrm{a}}$.

CIRULLI, M.; AMENDUNI, M.; COLELLA, C.; EL-SHAER, E.; D'AMICO M. Ricerca di portinnesti resistenti alla tracheoverticiliosi. Italus Hortus, Roma, v.8, p.50-52, 2001.

DEJONG T.M.; JOHNSON, R.S.; DOYLE, J.F.; WEIBEL, A.; SOLARI, L. Growth, yield and physiological behaviour of size controlling peach rootstocks developed in California. In: INTERNATIONAL SYMPOSIUM ON ROOTSTOCKS FOR DECIDUOUS FRUIT TREE SPECIES, 1., 2002, Zaragoza Proceedings...

EREMIN, V.; EREMIN, G. The perspective of clonal rootstocks for Prunus at Krymsk Breeding Station, Russia. In: INTERNATIONAL SYMPOSIUM ON ROOTSTOCKS FOR DECIDUOUS FRUIT TREE SPECIES, 1., 2002, Zaragoza. Proceedings...

FEI, C.; MASSAI, R.; LORETI, F. Preliminary observations on nine peach roostostocks grown a replant soil. In: INTERNATIONAL SYMPOSIUM ON ROOTSTOCKS FOR DECIDUOUS FRUIT TREE SPECIES, 1., 2002, Zaragoza. Proceedings...
GONZALES BERBEGAL S.; GÓMEZ APARISI J.; CARRERA, M.; SOCIAS I COMPANY, R. New results on the performance of new almond $\mathrm{x}$ peach hybrid rootstocks resistant to nematodes on tree growth and cropping. In: INTERNATIONAL SYMPOSIUM ON ROOTSTOCKS FOR DECIDUOUS FRUIT TREE SPECIES, 1., 2002, Zaragoza. Proceedings...

GRASSELLY, R.C. Selection of peach seedlings rootstocks. Acta Horticulturae, Wageningen, v.173, p.245-250, 1985.

IGLESIAS, L, MONTSERRAT, R.; GARBO', J.; BONANY, J.; CASALS, M. Evaluation of agronomical performance of several peach rootstocks in Lleida and Girona (Catalonia-Spain). In: INTERNATIONAL SYMPOSIUM ON ROOTSTOCKS FOR DECIDUOUS FRUIT TREE SPECIES, 1., 2002, Zaragoza. Proceedings...

INDREIAS, A.; DUTU, I.; STEFAN, I. Peach rootstocks created and used in Romania. In: INTERNATIONAL SYMPOSIUM ON ROOTSTOCKSFOR DECIDUOUSFRUIT TREE SPECIES, 1.,2002, Zaragoza. Proceedings...

JACOB, H. Prunus pumila, eine geeignete schwachwachsende. Erwerbsobstau, Pfirsichunterlage, v.34, p.144-146, 1992.

LORETI, F. Presente e futuro dei portinnesti degli alberi da frutto. Rivista di Frutticoltura, Bologna, v.1-2, p.77-86, 1988.

LORETI, F. Attuali conoscenze sui principali portinnesti degli alberi da frutto. Rivista di Frutticoltura, Bologna, v.9, p.9-60, 1994.

LORETI, F.; MASSAI, R. Sirio: nuovo portinnesto ibrido pesco x mandorlo. L'Informatore Agrario, Verona, v.28, p.47-49, 1994.

LORETI, F.; MASSAI, R. Orientamenti per la scelta dei portinnesti del pesco. L'Informatore Agrário, Verona, v.32, p. 37-42, 1995. Supplemento

LORETI, F.; MASSAI, R. I portinnesti del pesco. L'Informatore Agrário, Verona, v. 51, p. 37-42, 2002. Suplemento.

LORETI, F.; MASSAI, R. State of the art on peach rootstocks and orchard systems., Acta Horticulturae, Wageninge, n.713, p.253-268, 2006.

MASSAI, R.; LORETI, F.; FEI, C. Evaluation of new peach x almond hybrid rootstocks. In: INTERNATIONAL SYMPOSIUM ON ROOTSTOCKS FOR DECIDUOUS FRUIT TREE SPECIES, 1., 2002, Zaragoza. Proceedings...

MASSAI, R.; PELLEGRINO, S.; STROCCO, S. Nuove selezioni di pesco franco a confronto in Piemonte. Cesena: Ministero delle Risorse Agricole, Alimentari e Forestali, 1996. p.136-137. 
MORENO, M.A. Mejora selecciòn de patrones frulales de hueso en la estaciòn esperimental de Aula Dei. ITEA, v. 99, n.1, p.11-22, 2003.

PELLEGRINO, S.; MASSAI, R.; LORETI, F.; STROCCO, S. Comportamento bio-agronomico di alcune selezioni di pesco franco innestate con la cv. "Maria Bianca". Rivista di Frutticoltura, Bologna, v.11, p.47-50, 1997.

PINOCHET, J.; FERNANDEZ, C.; CUMILL, M.; TORRENTS, J.; FELIPE, A.; LOPEZ, M.M.; LASTRA, B.; PENYALER, R. Response of new interspecific hybrids for peach to rootknot and lesion nematodes, and crown gall. Acta Horticulturae, Wageningen, v.592.n.2, p.707-716.2002.

REIGHARD, G.L.; NEWALL, W.C.; BECKMAN, T.G.; OKIE, W.R.; ZEHR, E.I.; NYCZEPIR, A.P. Field performance of Prunus rootstock cultivars and selections on replant soils in South Carolina. Acta Horticulturae, Wageningen, v.451, p.243-250, 1997.

REIGHARD, G.L.; OULLETTE, D.R.; BROCK, K. K, NEWALL JR, W.C.; BECKMAN, T.G. Field testing peach rootstock selections for tolerance to peach tree short life and replant sites in South California. In: INTERNATIONAL SYMPOSIUM ON ROOTSTOCKSFORDECIDUOUSFRUIT TREE SPECIES, 1., 2002, Zaragoza. Proceedings...
RODRIGUEZ NAVARRO, J. Stone fruit trees rootstocks selection in the CIDA-Murcia. In: INTERNATIONAL SYMPOSIUM ON ROOTSTOCKSFOR DECIDUOUSFRUIT TREE SPECIES, 1., 2002, Zaragoza. Proceedings...

RODRIGUEZ, NAVARRO J.; CARRILLO NAVARRO, A. Pomologic and agronomie characteristics of the hybrid peachalmond Mayor ${ }^{\circledR}$. In: INTERNATIONAL SYMPOSIUM ON ROOTSTOCKSFOR DECIDUOUSFRUIT TREE SPECIES, 1., 2002, Zaragoza. Proceedings...

SALESSES, G.;; DIRLEWNGER, E.; BONNET,A.; LECOULS,A.C.; ESMENJAUD, D. Interspecific hybridization and roostostock breeding for peach. Acta Horticulturae, Wageninge, n.465, p.209$217,1908$.

WANG, L.; ZHU, G.; FANG, W. Peach germplasm and breeding programs at Zhengzhou in China. Acta Horticulturae, Wageningen, n.592, p.177-182, 2002.

WEIBEL,A.; PIZZOLATO, D.; DI CESARE, L.; OCHOA L. Peach orchard: hybrid rootstocks a good alternative for arid areas of Argentina. In: INTERNATIONAL SYMPOSIUM ON ROOTSTOCKSFORDECIDUOUSFRUIT TREE SPECIES, 1.,2002, Zaragoza. Proceedings...

ZOINA, A., RAIO, A. Susceptibility of some peach roostocks to crown gall. Journal of Plant Pathology, Siena, v.3, p.181-187, 1999. 